УДК 556.334

\title{
ГАЗОДИНАМИЧЕСКАЯ ХАРАКТЕРИСТИКА КОЛЛЕКТОРОВ ВО ВНЕШНЕМ КОНТУРЕ МЕСТОРОЖДЕНИЯ «ТРУБКА ИНТЕРНАЦИОНАЛЬНАЯ»
}

\author{
А. М. Янников \\ Воронежский государственный университет \\ Поступила в редакцию 16 октября 2018 г.
}

\begin{abstract}
Аннотация: приведена газодинамическая характеристика коллекторов толбачанской свиты в околотрубочном массиве трубки «Интерначиональная». Рассмотрены и изучены основные аспекты газоносности выделенных коллекторов. На основании работ проведенных в 2016-2017 годах проведена характеристика выделенных коллекторов, приведены параметры общей пористости, типы пористости. В разрезе пород толбачанской свиты выделены три зоны: газонасыщенная, «сухая», газоводонасыщенная. Каждая выделенная зона характеризуется сложным строением и состочт из нескольких характеристических интервалов.. Коллектора толбачанской свить характеризуются достаточно высокой газообильностью и высокими пластовыми давлениями. Поэтому, при дальнейшей разработке глубоких горизонтов в отложениях толбачанской свить необходимо предусматривать опережающее бурение для раздегазации вмещающего массива.

Ключевые слова: Непско-Ботуобинская антеклиза, Мирнинский выступ, месторождение трубки «Интернациональная», толбачанская свита, малодебитные трещиноватые коллектора.
\end{abstract}

\section{THE GASDYNAMIC CHARACTERISTIC OF THE COLLECTORS IN EXTERNAL CIRCUIT OF FIELD THE «TUBE INTERNATIONAL»}

\begin{abstract}
In the article the gas dynamic characteristics of the collectors of the Vulbachan suite in the okolotrubochnom array tube "International". The main aspects of the gas content of the identified reservoirs are considered and studied. Based on the work carried out in 2016-2017, the characteristics of the separated reservoirs are given, the parameters of the total porosity, the type of porosity, are given. In the context of the rocks of the Tolbachaya Formation, three zones are distinguished and characterized: gassaturated, "dry», gas-saturated. Each selected zone is characterized by a complex structure and consists of several characteristic intervals. The collector of the Tolbachanskaya suite is characterized by rather high gas abundance and high reservoir pressures. Therefore, in the further development of deep horizons in the sediments of the Tolbachan Formation, it is necessary to provide for advanced drilling for dressing the host massif.
\end{abstract}

Key words: Nepsko-Botuobinsky anteklise, Mirninsky ledge, field of a tube «International», tolbachanskaya suite, low-yield fissured collectors.

Целью данной работы является газодинамическая характеристика толбачанской свиты, в пределах околотрубочного пространства коренного месторождения алмазов трубка «Интернациональная», относящегося к мирнинскому кимберлитовому полю, входящему в якутскую алмазоносную провинцию.

В пределах околотрубочного пространства коренного месторождения трубка «Интернациональная» глубина залегания толбачанской свиты от дневной поверхности составляет 1065,0 м (а.о. кровли 665 м). Глубина залегания эльгянской свиты - 1442,5 м (а.о. кровли $-1042,5$ м)
Характеристика пород изучаемой свиты проведена в результате комплексного анализа и интерпретации проведенного комплекса работ. Включавшего в себя: постановки пластоиспытателей КИИ-65, газового каротажа и лабораторных работ (определение пористости, проведенное в ОАО НПП ВНИИГИС) по отобранным образцам горных пород.

Толбачанская свита $\left(\epsilon_{1}\right.$ tb) согласно залегает на породах эльгянской свиты $[1,2]$, сложена доломитами с прослоями известняков, ангидритов, каменной соли и мергелей. Отложения представлены галогеннокарбонатными породами: галитом, доломитами, до- 
ломитами глинистыми и доломитами известковистыми [3].

Массив отложений толбачанской свиты условно можно разделить на три пачки (снизу вверх):

- нижняя пачка - карбонатная с прослоем каменной соли мощностью 7,7 м. Обильное нефтенасыщение отмечается в доломитах известковистых;

- средняя пачка - карбонатная, представленная доломитами плотными мелко-тонкозернистыми, слоистыми с прослоями доломитов глинистых и доломито-ангидритов засолоненных. Нефтенасыщенность в виде пятен (выпоты по трещинам, порам) тёмно- коричневого цвета $[4,5]$;

- верхняя пачка - галогенно-карбонатная с соленасыщенностью до 50 \%, с включениями твердых битумов.

По результатам скважинной геофизики по обеим скважинам в отложениях выделяется 15 коллекторов [6].

Мощность пластов коллекторов изменяется от 0,5 до 7,0 м. Общая мощность газо-водонасыщенных коллекторов толбачанской свиты составляет от 95 до 110 м [7]. Характеристика выделенных коллекторов приведена в табл. 1.

Таблица 1

Характеристика коллекторов толбачанского газо-водоносного комплекса

\begin{tabular}{|c|c|c|c|c|c|}
\hline №№ коллектора & Кровля, м & Подошва, м & Мощность, м & Пористость, \% & Примечание \\
\hline 1 & 1175,0 & 1177,0 & 2,0 & 2,7 & Водонасыщенный \\
\hline 2 & 1195,0 & 1197,5 & 2,5 & 2,4 & Газонасыщенный \\
\hline 3 & 1198,5 & 1200,0 & 1,5 & 3,6 & Газонасыщенный \\
\hline 4 & 1211,8 & 1213,0 & 1,2 & 11,6 & Водонасыщенный \\
\hline 5 & 1221,0 & 1225,5 & 4,5 & 5,8 & Газонасыщенный \\
\hline 6 & 1237,8 & 1238,8 & 1,0 & 11,7 & Водонасыщенный \\
\hline 7 & 1243,0 & 1244,4 & 1,4 & 11,3 & Водонасыщенный \\
\hline \multirow{6}{*}{8} & 1264,0 & 1265,0 & 1,0 & 6,8 & \multirow{6}{*}{$\begin{array}{c}\text { Газо-водо- } \\
\text { насыщенный }\end{array}$} \\
\hline & 1266,5 & 1267,2 & 0,7 & 9,2 & \\
\hline & 1272,2 & 1274,2 & 2,0 & 6,7 & \\
\hline & 1274,3 & 1275,0 & 0,7 & 8,9 & \\
\hline & 1281,0 & 1282,5 & 1,5 & 5,9 & \\
\hline & 1285,0 & 1292,0 & 7,0 & 6,6 & \\
\hline \multirow{7}{*}{9} & 1296,5 & 1298,0 & 1,5 & 2,9 & \multirow{7}{*}{$\begin{array}{c}\text { Газо-водо- } \\
\text { насыщенный }\end{array}$} \\
\hline & 1299,8 & 1300,6 & 0,8 & 8,1 & \\
\hline & 1301,0 & 1306,0 & 5,0 & 5,2 & \\
\hline & 1306,8 & 1307,6 & 0,8 & 10,7 & \\
\hline & 1308,5 & 1315,5 & 7,0 & 9,8 & \\
\hline & 1318,8 & 1319,8 & 1,0 & 9,2 & \\
\hline & 1319,8 & 1321,8 & 2,0 & 2,9 & \\
\hline \multirow{5}{*}{10} & 1324,5 & 1326,5 & 2,0 & 3,1 & \multirow{5}{*}{$\begin{array}{c}\text { Слабогазо- } \\
\text { насыщенный } \\
\text { «сухой» }\end{array}$} \\
\hline & 1328,5 & 1330,5 & 2,0 & 2,9 & \\
\hline & 1332,5 & 1335,5 & 3,0 & 2,7 & \\
\hline & 1338,5 & 1341,5 & 3,0 & 5,8 & \\
\hline & 1343,0 & 1345,0 & 2,0 & 3,1 & \\
\hline \multirow{2}{*}{11} & 1347,0 & 1350,0 & 3,0 & 5,6 & \multirow{2}{*}{$\begin{array}{c}\text { Слабогазо- } \\
\text { насыщенный } \\
\text { «сухой» }\end{array}$} \\
\hline & 1352,5 & 1354,5 & 2,0 & 7,2 & \\
\hline \multirow{2}{*}{12} & 1359,0 & 1361,0 & 2,0 & 2,9 & \multirow{2}{*}{ Газонасыщенный } \\
\hline & 1363,5 & 1390,5 & 27,0 & 6,2 & \\
\hline \multirow{3}{*}{13} & 1395,0 & 1401,0 & 6,0 & 4,4 & \multirow{3}{*}{ Газонасыщенный } \\
\hline & 1404,0 & 1406,0 & 2,0 & 3,3 & \\
\hline & 1407,0 & 1412,0 & 5,0 & 4,1 & \\
\hline \multirow{2}{*}{14} & 1422,0 & 1425,0 & 3,0 & 3,7 & \multirow{2}{*}{ Газо-водонасыщенный } \\
\hline & 1428,3 & 1429,0 & 0,7 & 9,3 & \\
\hline \multirow{3}{*}{15} & 1435,6 & 1436,4 & 0,8 & 10,2 & \multirow{2}{*}{ Газо-водонасыщенный } \\
\hline & 1438,0 & 1440,0 & 2,0 & 2,8 & \\
\hline & \multicolumn{2}{|c|}{ Эфффективная мочңность, м: } & 110,6 & 6,1 & \\
\hline
\end{tabular}


Проведя комплексный анализ проведенных работ, в разрезе толбачанской свиты было выделено три зоны: газонасыщенная, практически «сухая» и газоводонасыщенная. Каждая выделенная зона характеризуется сложным строением и состоит из нескольких характеристических интервалов (рис. 1).

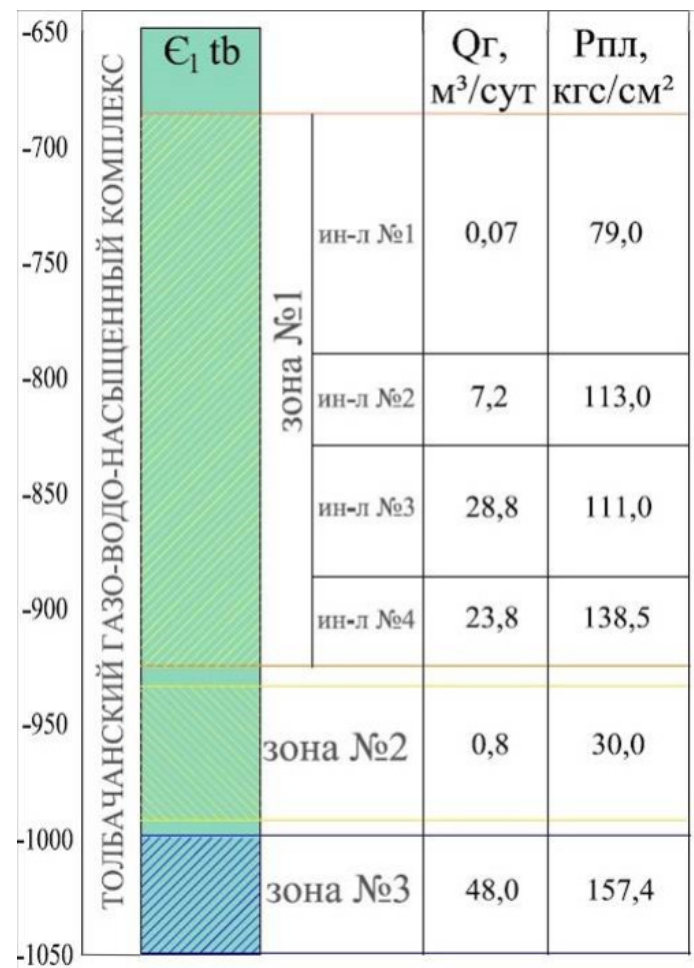

Рuc. 1. Схематичное расположение (в разрезе) выделенных зон.

Зона №1 - Газонасыщенная зона выделяется в интервале 1067,0-1320,0 м. (-667,2м) - (-920,3м) по степени газонасыщения в свою очередь подразделяется на четыре интервала:

- интервал 1067,0-1190,0м (абс. отм. (-667,3 м) - (790,3 м): галогенно-сульфатно-карбонатная толща с включениями твёрдых битумов. По данным ГИС на данном интервале выделен один маломощный пластколлектор №1, мощностью 2,0 м. Приток флюида открытом периоде при снятии давления Q до 0,07 м³/сут; расчётное пластовое давление Рпл. - 79,0 кгс/см²; коэффициент газопроводности $\frac{k h}{\mu}-0,003$ Дсм/спз;

- интервал 1190,0-1230,0 м (абс. отм. (-790,3 м) (-830,3 м): галогенно-сульфатно-карбонатная толща с включениями твёрдых битумов. По данным ГИС на данном интервале выделено четыре коллектора №№ 2, 3, 4 и 5, общей мощностью 9,7 м. Приток газа Qг до 7,2 м 3 /сут; расчётное пластовое давление Рпл. - 113,0 кгс/см ${ }^{2} ;$ коэффициент газопроводности $\frac{k h}{\mu}-0,56$ Дсм/спз;
- интервал 1231,8-1280,0 м (абс. отм. (-832,1 м) (-880,3 м): карбонатная толща с редкими выпотами нефти. По данным ГИС на данном интервале выделено три коллектора №№ 6, 7 и 8, общей мощностью 15,3 м. Приток газа Qг до $28,8 \mathrm{~m}^{3} /$ сут; расчётное пла-

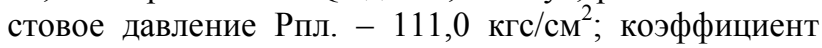
газопроводности $\frac{k h}{\mu}-1,24$ Дсм/спз;

- интервал 1280,0-1320,0 м (абс. отм. (-880,3 м) $(-920,3$ м): карбонатная толща с более обильным нефтенасыщением. По данным ГИС на данном интервале выделен один коллектор №9, состоящий из 7 платов. Общая мощность коллектора №9 составляет 18,1 м. Приток газа Qг до 23,8 м³/сут; расчётное пла-

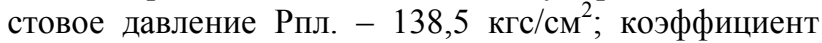
газопроводности $\frac{k h}{\mu}-0,24$ Дсм/спз;

Зона №2 - «Сухая» зона в интервале 1320,0-1390,0 м (абс. отм. (-920,3 м) - (-990,3 м) представлена глинисто-сульфатно-карбонатной толщей. По данным ГИС на данном интервале выделено два коллектора №№ 10 и 11, общей мощностью порядка 46 м. Приток газа составляет Qг до 0,8 м 3 ссут; расчётным пласто-

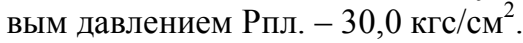

Зона №3 - Газо-водонасыщенная зона выделяется в интервале 1390,0-1442,5 (абс.отм. (-990,3 м) - (1042,8 м) сложена карбонатными и глинистокарбонатными толщами, с редкими выпотами нефти. По данным ГИС на данном интервале выделено три коллектора №№ 12, 13, 14 и 15, общей мощностью порядка 19,5 м. Приток газа Qг до 48,0 м³/сут; пласто-

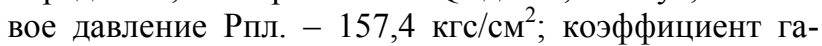
зо(гидро)проводности $\frac{k h}{\mu}-3,12$ Дсм/спз.

Проведя обработку и анализ выполненных гидрогеологических работ, изучив результаты натурных наблюдений, и проанализировав, с последующей интерпретацией, результаты опробования, правомерным будет сделать ряд следующих выводов и обобщений:

1. Подтверждена главенствующая роль коллекторов толбачанской свиты, в формировании сложных условий отработки добычных X, XI и XII блоков, в отм. /-790/ - /-1050/ месторождения трубка «Интернациональная».

2. В целом, по разрезу, карбонатная толща отличается большим разнообразием структурно-генетических типов, изменчивостью литологического состава пород и фильтрационно-емкостными свойствами. Формирование коллекторов различных типов обусловлено разнофациальным характером отложений. Это проявляется в значительной неоднородности строения. Интенсивно проявившиеся процессы залечивания первичных пустот кальцитом, ангидритом, солью, а также перекристаллизации первичного осадка, значительно усложнили строение порового пространства, за счет чего высокопористые разности частично утратили свою емкость. Процессы доломити- 
зации, выщелачивания и трещинообразования обеспечили развитие дополнительных видов пустот и способствовали формированию сложных типов коллекторов. И, как следствие, формированию «линзмикрозалежей».

3. Учитывая сложное геологическое строение шахтного поля, наличие многочисленных нарушенных блоков, можно допустить, что потенциальные газовые скопления, которые существуют в пачках межсолевых отложений в случае предельного насыщения воды и нефти природными газами, имеют весьма ограниченные размеры.

4. Коллектора толбачанской свиты характеризуются достаточно высокой газообильностью и высокими пластовыми давлениями. Поэтому, при дальнейшей разработке глубоких горизонтов в отложениях толбачанской свиты необходимо предусматривать опережающее бурение для раздегазации вмещающего массива. Проектирование дегазационных скважин, расчёт длин кондукторов, опрессовочных давлений и устьевых обвязок необходимо производить согласно выделенных в разрезе толбачанской свиты зон.

5. Произведённая характеристика выделенных газоносных коллекторов толбачанской свиты в околотрубочном массиве трубки «Интернациональная», является неотъемлемой частью изучения газодинамических, гидрогеологических условий толбачанской свиты, слагающей массив вмещающих горных пород трубки «Интернациональная» в интервале от (-790) до (-1042) м. Необходимость изучения пород данной свиты продиктована безопасной отработкой данного месторождения, и накопления опыта для последующей отработки других месторождений (в том числе алмазоносных трубок).

\section{ЛИТЕРАТУРА}

1. Колганов, В. Ф. Горно-геологические особенности коренных месторождений алмазов Якутии / В. Ф. Колганов, А. Н. Акишев, А. В. Дроздов // Мирный, 2013. - С. 96-121.

2. Гидрогеология СССР. Том ХХ. Якутская АССР. - М.: Недра, 1970. - С. 83-100.

3. Материалы к легенде Ботуобинской серии листов геологических карт масштаба 1:50000. / Д. В. Блажкун [и др.] // Мирный. Ботуобинской ГРЭ ПГО «Якутскгеология» Министерства геологии СССР, 1989 г. - 70 с.

4. Геология, гидрогеология и геохимия нефти и газа южного склона Анабарской антеклизы / Е.И. Бодунов [и др.] Якутск: изд. ЯФ СО АН СССР, 1986.- 176 с.

5. Зуева, И. Н. Химическая структура нафтидов. ДалдыноАлакитского района. (По данным ИК- и УФ-спектроскопии) / И. Н Зуева, Н. А. Уткина, Е. И. Бодунов // - Якутск: изд. ЯФ СО АН СССР, 1987.- С. 99-110.

6. Янников, А. М. Интенсивность и продолжительность самоизлива пластовых вод из малодебитных коллекторов толбачанской свиты. / А. М Янников // Вестник Воронеж. гос. ун-та. - Сер.: Геология - 2018. - №1. - С. 139-141.

7. Иост, Н. А. Гидрогеологическая характеристика отложений толбачанской свиты в околотрубочном пространстве месторождения трубка «Интернациональная». / Н. А. Иост, А. М. Янников // Сборник докладов VIII-й Всероссийской научно-практической конференции студентов, аспирантов и молодых учёных "Молодежь и научно-технический прогресс в современном мире". - Мирный. 2017 - С. 201-205.

\section{АК «АЛРОСА» ПАО, республика Саха-Якутия, г. Мирный}

Янников Алексей Михайлович, Ведущий гидрогеолог Вилюйской ГРЭ, аспирант кафедры гидрогеологии, инженерной геологии и геоэкологии Воронежского государственного университета

E-mail: yannikov90@mail.ru

Тел: +79148259885

\section{AK "ALROSA" PAO, Republic of Sakha-Yakutia, Mirny}

Yannikov A. M., Senior hydrogeologist Vilyui GRE, graduate of the Department of hydrogeology, engineering Geology and Geoecology of Voronezh State University

E-mail:yannikov90@mail.ru

Тел: +79148259885 